\title{
Las perífrasis verbales y las locuciones verbales en la diacronía del español ${ }^{1}$
}

\author{
Mar Garachana Camarero ${ }^{2}$ \\ Universitat de Barcelona, España \\ Axel Hernández Díaz \\ Universidad Nacional Autónoma de México, México
}

Los artículos que integran esta monografía se centran en el estudio de la evolución de las perífrasis verbales del español. Asimismo, se da cabida a la diacronía de las locuciones verbales. Así pues, el objetivo último del volumen es contribuir a llenar un vacío importante en el conocimiento de la gramática histórica del español, habida cuenta de que los estudios históricos acerca de estas dos categorías gramaticales son todavía hoy poco numerosos. En este sentido, los trabajos incorporados a este volumen se suman a los publicados en 2017 en una monografía sobre la diacronía de las perífrasis verbales que recogía la investigación desarrollada por el grupo de investigación GRADIA (Garachana 2017).

1 Esta monografía se ha llevado a cabo en el marco de los proyectos de investigación Diccionario histórico de las perífrasis verbales del español. Gramática, pragmática y discurso del MINECO (FFI2016-77397-P) y Gradia. Grup de Gramàtica i Diacronia (2017 SGR 01337) del AGAUR.

2 Para correspondencia, dirigirse a: Mar Garachana Camarero (margarachana@ub.edu), Universidad de Barcelona. Gran Via de les Corts Catalanes, 585. 08007 Barcelona. España.

3 Para correspondencia, dirigirse a: Axel Hernández Díaz (axel.hernandez@comunidad. unam.mx), Facultad de Filosofía y Letras. Universidad Nacional Autónoma de México. Circuito Interior. Ciudad Universitaria, s/n, C.P. 04510, Coyoacán, Ciudad de México, México. 
El objetivo principal de GRADIA (https://Gradiadiacronia.wixsite.com/ Gradia) es el análisis de la diacronía de las perífrasis verbales del español desde sus orígenes latinos. En esta actividad investigadora, GRADIA ha buscado sinergias con otros grupos interesados también en el estudio de la evolución de las construcciones multiverbales (en el sentido de Aikhenvald 2011) o de las locuciones verbales. De ahí la estrecha colaboración que se está manteniendo con la Pontificia Universidad Católica de Chile, con la Universidad de Chile, con la Universidad Católica del Maule y con el College of the Holy Cross. La presente monografía es un reflejo de dicha cooperación entre grupos de investigación, iniciada en abril de 2018 en un encuentro celebrado en la UNAM que fue coorganizado por esta institución y la Universitat de Barcelona.

El grueso de los trabajos de esta sección monográfica del Boletín de Filología de la Universidad de Chile se centra en las perífrasis y las locuciones verbales formadas a partir de verbos de movimiento o de verbos que implican algún tipo de desplazamiento físico. Así, se analiza la evolución de las perífrasis andar + GER, poner(se) a + INF, llegar y + VERBO FINITO y llegar $a+$ INF y la de locuciones verbales del tipo venirle en voluntad. Asimismo, se han incluido trabajos sobre soleo/soler $+\mathrm{INF}$, empezar $a+\mathrm{INF}$ y comenzar $a+$ INF.

Como se deduce de la nómina de construcciones analizadas, esta monografía abarca estructuras que encajan bien en lo que la gramática tradicional considera que es una perífrasis verbal prototípica (soler + INF, andar + GER, llegar $a+\mathrm{INF}$ ); construcciones menos representativas, dado que su verbo auxiliar todavía mantiene fuertes lazos semánticos con el verbo léxico del que procede (empezar $a+\mathrm{INF}$ y comenzar $a+\mathrm{INF}$ ); perífrasis cuya reducida combinatoria las aleja del centro nuclear de la categoría (ponerse a + INF); así como estructuras que tradicionalmente habían quedado fuera de la nómina de las perífrasis verbales (llegar y + VERBO FINITO). La presencia de todos estos tipos de construcciones verbales permite deducir que se ha optado por una consideración amplia de lo que es una perífrasis verbal, entendida en términos de prototipicidad. Las diferencias que inevitablemente existen entre construcciones con auxiliados no finitos y auxiliados finitos se pueden salvar, tal y como se propone en Jaque et al. ( $\rightarrow$ este volumen), desde el concepto de construcción multiverbal, que acoge tanto a las perífrasis tradicionales como a las estructuras que escapan a la forma propia de estas (Aikhenvald 2011). El paralelismo funcional y semántico que se observa entre todas estas estructuras verbales justifica su inclusión en una monografía sobre perífrasis verbales.

La elección de estas construcciones no ha sido fruto del azar, sino resultado de la reflexión teórica acerca de la constitución y la evolución del 
sistema perifrástico del español. En lo relativo a las perífrasis surgidas a partir de verbos de movimiento, el interés responde a que uno de los grupos más numerosos de perífrasis verbales del castellano es, precisamente, el que presenta verbos auxiliares procedentes de antiguos verbos léxicos que significaban algún tipo de desplazamiento o cambio de posición. La predilección de nuestra lengua por este tipo de construcciones ha motivado, incluso, la existencia de perífrasis cuasisinónimas cuyo auxiliar es un verbo de estas características semánticas (pensemos, por ejemplo, en alcanzar a + INF y llegar $a+\mathrm{INF}$ ). Más aún, algunos verbos de movimiento han dado lugar a más de una perífrasis. Es el caso de andar, ir o venir, por poner solo tres ejemplos, que se han gramaticalizado en las construcciones andar $a+\mathrm{INF}$, andar + GER, andar + PART; ir $a+$ INF, ir + GER, ir + PART, ir $y+$ VERBO FINITO; venir $a+\mathrm{INF}$, venir + GER, venir y + VERBO FINITO y venir + PART.

La reflexión sobre la evolución de soleo/soler + INF se justifica desde una postura metodológica que lleva a insistir en el hecho de que la historia de las perífrasis del español debe hacerse desde el latín, siempre que sea posible. Este procedimiento metodológico es un requisito indispensable para el estudio evolutivo de la gramática de las lenguas románicas, pues arroja luz sobre el empleo medieval, pero también contemporáneo, de muchas formas gramaticales del español. Por ejemplo, los trabajos de Cabré y Artigas ponen sobre la pista del valor de ciertos usos medievales de soler + INF -mantenidos en la lengua contemporánea- que habían sido calificados de redundantes. Bajo el prisma del latín, estos valores, aparentemente expletivos, encajan mejor en una descripción relacionada con la caracterización del sujeto de la predicación. Así, la perífrasis soler + INF, en el verso de una canción de amor como ¿Te besa ella como yo solía hacerlo? no parece que haga referencia a que la antigua amante unas veces besaba a su ex de manera apasionada y otras no. Más bien, ese yo solía hacerlo remite a una manera de hacer que era característica de la persona que profiere este enunciado; de ahí que podamos considerar que algunos de los usos de soler + INF pueden ser calificados como tipificadores o caracterizadores (vid. los trabajos de Cabré y de Artigas en este volumen). Se suma este ejemplo a otros previos que ponen de relieve la necesidad de partir de los valores latinos para interpretar adecuadamente la historia de las perífrasis verbales (cf. Artigas y Cabré 2017).

Por último, el estudio de las construcciones idiomáticas del tipo venirle en gana responde al interés de analizar procesos de cambio en los que verbos de movimiento se vean implicados a fin de encontrar puntos de contacto en la evolución del léxico y de la gramática. El estudio conjunto de perífrasis verbales y de locuciones verbales tiene, pues, una motivación teórica: la de mostrar que los límites entre unas construcciones y otras resulta tenue en muchas ocasiones. La proximidad entre ambos tipos de estructuras verbales 
puede medirse de acuerdo con al menos dos factores. Para empezar, el punto de partida de las perífrasis verbales, cuando es posible rastrear su origen, suele ser una construcción idiomática. Esto resulta muy claro para haber que + INF, nacida de la locución haber que ver 'tener relación, especialmente sexual' (Garachana Camarero 2016). En segundo lugar, los valores expresados por algunas construcciones idiomáticas no están completamente alejados de sentidos gramaticales. Así, en este monográfico Josep Alba se refiere a los sentidos incoativos de venir en + sust y Garachana señala los límites difusos entre el léxico y la gramática marcados por la construcción llegar a ser como estructura equivalente a los verbos (semi)copulativos devenir (francés) y become (inglés). En la misma línea, Brinton $(2008,2011)$ señaló que, cuando los verbos soporte constituyen locuciones verbales, el proceso evolutivo experimentado por estas tiene que ver con procesos de gramaticalización. Además, según Brinton, los significados que expresan dichas locuciones tienen propiedades y un rendimiento funcional que las aproximan a las partículas gramaticales.

En este punto, se justifica también el enfoque construccionalista que se observa en varias de las aportaciones al monográfico. En efecto, uno de los puntales básicos de la gramática de construcciones, también de la diacrónica, es el de señalar la existencia de un continuum entre el léxico y la gramática (Fillmore 1988; Fillmore y Kay 1997; Fillmore, Kay, y O’Connor 1988; Goldberg 1995, 2006; Fried 2009; Enghels y Garachana 2020). Este continuum permite proponer un mismo utillaje de trabajo para el estudio de la evolución que culmina en el léxico y en la gramática.

Por lo tanto, en algunos de los trabajos que integran este volumen colectivo, se observará una metodología estrictamente característica de la teoría de la gramaticalización. En otros, en cambio, operará una metodología en la que la gramaticalización se aborda desde el enfoque de la gramática de construcciones diacrónica. En este segundo caso, lo que ha importado ha sido explicar los procesos de cambio gramatical tratando de determinar si se trata de cambios construccionales o de construccionalizaciones. Siguiendo a Traugott y Trousdale (2013), entendemos el cambio construccional como la modificación o bien del significado o bien de la forma que precede o sigue a la aparición de una nueva construcción gramatical, entendida en el sentido de la gramática de construcciones, a saber, como el emparejamiento convencionalizado de una forma y un significado (Goldberg 1995, 2006). La construccionalización, en cambio, es una evolución que vincula un nuevo significado a una nueva forma, con la consiguiente emergencia de una nueva construcción gramatical. Así pues, el cambio gramatical propiamente tal se produce en la construccionalización. En este punto, queremos remarcar que esta monografía constituye uno de los primeros ensayos para aplicar 
la metodología de la gramática de construcciones diacrónica al estudio de la gramática del español. Con todo, los trabajos que integran este volumen tienen como fin último la redacción del Diccionario histórico de perífrasis verbales del español, que es uno de los objetivos perseguidos por el grupo GRADIA y por sus colaboradores.

La organización interna del monográfico responde a cuestiones cronológicas y vinculadas al tipo de construcción que se estudia en cada contribución. Así, iniciamos el monográfico con dos trabajos que abordan las perífrasis verbales desde sus orígenes y antecedentes latinos. Los restantes trabajos se organizan en función de la semántica de los verbos de los que proceden los auxiliares de las construcciones analizadas. En primer lugar, se presentan perífrasis que no se crearon a partir de verbos de movimiento, para, en segundo lugar, introducir las que sí se formaron desde este tipo de formas verbales. El monográfico concluye con el trabajo dedicado a la evolución de las locuciones verbales.

Los primeros dos trabajos presentados están centrados, como dijimos, en la diacronía y los antecedentes latinos de las construcciones perifrásticas en torno al verbo latino soleo, que dio origen al verbo soler en español y a la perífrasis soler + INF. Abre el monográfico el trabajo de Laura Cabré, quien demuestra que, para entender el patrón evolutivo de la construcción soler + INF, resulta básico remontarse a la etimología del verbo latino soleo. La autora se decanta por la hipótesis que entronca soleo con la acepción de 'ser de uno, tener como propio, ser normal, ser costumbre', que en su opinión deja su impronta en la interpretación de la perífrasis romance.

A continuación, Esther Artigas ofrece un panorama amplio de las lecturas y valores que desarrolla en latín la construcción soleo + INF. De acuerdo con los testimonios aportados y el análisis de los distintos factores implicados en la interpretación de esta perífrasis en castellano, la autora muestra que su origen no está en la expresión del aspecto habitual frecuentativo que se menciona recurrentemente en la bibliografía, sino en un valor básico que corresponde propiamente al aspecto continuo. Este aspecto continuo permite entender y explicar algunos usos de la perífrasis en las primeras etapas de la lengua española.

El tercer trabajo, a cargo de Axel Hernández Díaz, aborda las perífrasis incoativas comenzar a y empezar a + INF a la luz de la teoría de gramaticalización. En él, se considera la importancia del significado léxico de las palabras en la construcción de piezas gramaticales. Concretamente, la autora plantea que la alternancia de las formas perifrásticas estudiadas muestra que las dos conviven actualmente y que su uso está condicionado por factores contextuales y cronológicos vinculados al uso pleno de los dos predicados. Asimismo, en este trabajo se sostiene que la evolución diacrónica 
de la perífrasis coincide con otros momentos clave en la evolución de las perífrasis en la lengua española.

El cuarto artículo, a cargo de Daniel Cuní, analiza la evolución de ponerse $a+\mathrm{INF}$ desde el modelo teórico de la gramática de construcciones diacrónica. De acuerdo con el autor, el origen de la construcción perifrástica se encuentra en estructuras causativas (poner el agua a hervir) que, a través de un proceso metonímico, permiten inferir el significado incoativo que caracteriza en la lengua moderna a la perífrasis. La propuesta de Cuní establece que la construcción poner el agua a hervir permite inferir que el evento de hervir dará inicio. En otras palabras, colocar el agua en un lugar para que se caliente es el paso previo para que esta hierva. Este cambio semántico fue acompañado de un cambio sintáctico consistente en la reorganización de la jerarquía de constituyentes de la estructura causativa. Al producirse un cambio en la forma y en el significado tiene lugar la emergencia en el siglo XIX de una nueva construcción gramatical en la lengua española.

El trabajo número cinco del monográfico, escrito por Dorien Nieuwenhuijsen, pone de relieve la importancia del enfoque dialectal a la hora de abordar el estudio de la diacronía de las perífrasis verbales. Concretamente, Nieuwenhuijsen examina la variación diatópica de la perífrasis andar + GER, comparando su uso en el español mexicano con su empleo en el español peninsular. De este modo, la autora prueba que la gramaticalización de andar + GER se desarrolló de manera diferente en función del entorno dialectal. El análisis cuantitativo contenido en este artículo pone de manifiesto la mayor frecuencia de la perífrasis en México y revela que se emplea, sobre todo, en modalidades de lengua informales. En el plano semántico, el estudio confirma que andar ha ido perdiendo su significado léxico de movimiento físico y ha llegado a transmitir valores pragmáticos, particularmente de determinación y empeño.

El sexto trabajo, redactado por Mar Garachana, estudia la evolución de la perífrasis verbal llegar $a+$ INF desde la perspectiva de la gramática de construcciones diacrónica. De acuerdo con la autora, llegar $a+$ INF es un esquema gramatical que se concreta en cinco microconstrucciones diferentes, a saber, la que expresa significados de conclusión o interrupción de una serie de eventos previa (Llegaron a aburrirse del tema), la que significa logro (Llegó a ganar el Tour de Francia 5 veces consecutivas), la que expresa (in)capacidad (Nunca llegaba a coger el tren a la hora prevista), la que recubre valores focalizadores (Llegó a decirme que estaba equivocado) y la que tiene valor de posibilidad (Solo llegaba a verse una parte de su rostro). Estas microconstrucciones permiten describir llegar $a+$ INF en términos de una categoría radial, cuyos miembros están unidos por un significado de trayectoria o de recorrido que remonta al valor léxico de llegar. Este trabajo 
muestra también la especial afinidad de llegar $a+$ INF por la modalidad negativa, de manera particular en los valores de logro y de capacidad, con lo que se diría que se está creando una especie de construcción especializada en la expresión de la frustratividad. Por último, un aspecto remarcable es la frecuente introducción de llegar $a+\mathrm{INF}$ en cadenas perifrásticas en las que esta perífrasis aparece como auxiliado del verbo poder (poder llegar a $+\mathrm{INF}$ ).

El séptimo trabajo, escrito por Matías Jaque, Carlos González Vergara, Silvana Guerrero, Felipe Hasler, Verónica Orqueda, Claudio Garrido y Magdalena Covarrubias aborda la evolución semántica de construcciones del tipo llegar y + FV en español. En él, se propone que su valor básico es el de aspecto interruptivo, a partir del que se habría desarrollado, como un sentido secundario, un valor admirativo. Los autores muestran también que los usos que expresan la ocurrencia abrupta de un evento tienen mayor profundidad histórica que los usos esporádicos y más recientes en los que se aprecia un valor admirativo que no depende de un valor aspectual primario. Este cambio se explica como un proceso de aumento de alcance en la jerarquía de operadores de la cláusula, idea común en los procesos de gramaticalización, tanto desde aproximaciones funcionales como formales.

Cierra el monográfico Josep Alba-Salas con un trabajo que, a diferencia de los anteriores, no aborda el estudio de una perífrasis verbal. Alba-Salas centra su estudio en el análisis de las colocaciones del tipo venirle en voluntad, que describe como un patrón construccional desaparecido en nuestra lengua. Pese a la productividad que mostraba en la Edad Media, este tipo de colocaciones cayó en desuso y se lexicalizó en el Siglo de Oro, dejando en la lengua española lo que el autor denomina reliquias fosilizadas, como venirle en gana(s) y otras expresiones de uso marginal. El trabajo describe los valores expresados por estas colocaciones, sus rasgos formales y los matices semánticos que adquirieron hasta lexicalizarse.

\section{REFERENCIAS BIBLIOGRÁFICAS}

AikHenvald, AleXandra Y. 2011. Multi-verb constructions: setting the scene. En Multi-verb constructions. A view from the Americas, pp. 1-26. Leiden: Brill.

Artigas Álvarez, Esther, y Laura Cabré Lunas. 2017. Saber no es soler en latín. A propósito del origen de la perífrasis "saber + infinitivo". En Mar Garachana (ed.). La gramática en la diacronía. La evolución de las perífrasis verbales modales en español, pp. 117-46. Madrid - Frankfurt: Iberoamericana-Vervuert.

Brinton, LAUREL J. 2008. Where grammar and lexis meet: composite predicates in English. En Elena Seoane y María José López-Couso (eds.). Theoretical and Empirical issues in grammaticalization, pp. 33-53. Amsterdam/Philadelphia: John Benjamins. 
2011. The grammaticalization of complex predicates. En Heiko Narrog y Bernd Heine (eds.). The Oxford Handbook of Grammaticalization, pp. 559-69. Oxford: Oxford University Press.

Enghels, Renata y Mar Garachana. 2020. Grammaticalization, lexicalization, and constructionalization. En Xu Wen y John R. Taylor (eds.). The Routledge Handbook of Cognitive Linguistics. London: Routledge.

Fillmore, Charles J. 1988. The mechanisms of 'Construction Grammar'. En Berkeley Linguistics Society 14: General Session and Parasession on Grammaticalization, pp. 35-55. Berkeley, CA: Berkeley Linguistics Society.

Fillmore, Charles J. y Paul Kay. 1997. Berkeley Construction Grammar. http://wwwl.icsi. berkeley.edu/ kay/bcg/ConGram.html.

Fillmore, Charles J., Paul Kay y Mary Catherine O’Connor. 1988. Regularity and idiomaticity in grammatical constructions. Language 64: 501-38.

Fried, Mirjam. 2009. Construction Grammar as a tool for diachronic analysis. Constructions and Frames. John Benjamins.

Garachana Camarero, Mar. 2016. Restricciones léxicas en la gramaticalización de las perífrasis verbales. Rilce 32 (1): 136-58.

2017. La gramática en la diacronía. La evolución de las perifrasis verbales modales en español. Madrid-Frankfurt: Iberoamericana-Vervuert.

Goldberg, Adele E. 1995. Constructions: A Construction Grammar Approach to Argument Structure. Chicago: Chicago University Press.

2006. Constructions at Work: The Nature of Generalization in Language. Oxford: Oxford University Press.

Traugott, Elizabeth Closs y Graeme Trousdale. 2013. Constructionalization and Constructional Changes. Oxford: Oxford University Press. 